\title{
2 \\ Critical Thinking and/or Argumentation in Higher Education
}

\author{
Richard Andrews
}

\section{Introduction}

Critical thinking and argumentation are closely allied. And yet each field has its own derivation and antecedents, and the differences between these are fundamental not only to debates today about their centrality in higher education, but to the entire history of the relationship (in Europe at least) between thought and language as well. On the one hand, critical thinking is most closely allied to philosophy; on the other, argumentation is allied with rhetoric. The debate about the relationship between philosophy and rhetoric goes back to Plato and Aristotle. It concerns ideas, ideals, concepts, and abstract thought and logic in relation to philosophy and the expression of these categories in verbal and other forms of language. Both critical thinking and argumentation overlap in their territories of engagement, and both have pedagogical implications for learning and teaching in higher education. This chapter explores the relationship, examines some examples at doctoral level (and briefly at undergraduate level), and puts the case for argumentation as the best focus in terms of taking forward practice in higher education. In doing so, it may run counter to the arguments in many of the chapters in this book, but the challenge presented in this chapter may act like the grit in the oyster. In Toulminian terms, the challenge can be rebutted or lead to a more qualified position on the role of critical thinking in higher education.

\section{Critical thinking}

The case for critical thinking starts with Lipman, because of his work with primary/elementary schoolteachers and children. The reason for starting here is that the fundamentals of critical and clear thinking are established at that point, and they prepare the ground for consideration of such approaches in higher education in a developmental sense. Lipman's work concentrates on 
thinking in education in the school, basing its approach on philosophy "when properly constructed and properly taught" $(2003,3)$. The thinking is to be taught within a community of inquiry and includes critical reflection. Lipman is skeptical of the notion of critical thinking, however, seeing it (as I do) as tautological. To think clearly is to be critical; being "critical" simply adds an epithet that is redundant. He notices a fading away of the critical thinking movement in the first part of the present century. In higher education, there has been a lack of theoretical work on thinking in the wake of mid-century adherence to Piagetian approaches to cognition and cognitive development and the publication of neo-Piagetian and Vygotskian approaches in the 1980s. Lipman argues that without such theoretical or historical examination critical thinking's claim to be a discipline "can hardly be persuasive" (ibid., 4). The present book addresses this perceived gap in theoretical work.

In higher education-and assuming that "thinking" is core to intellectual life-practice can be deemed to be "critical" if one is driven by (a) a spirit of inquiry and skepticism, (b) able to take criticism of one's colleagues and other academics' work as part of the fabric of intellectual exchange, and (c) is selfcritical. Half of these concepts I have taken from Lipman (2003, 16-17), while I have rejected others to do with "correction." Lipman's inclusion of categories of correction and self-correction suggests that his model of thinking and argumentation is too closely allied to the field of argument and thinking that concerns itself with fallacies. But the weakness of Lipman's position lies in the foundations of his reflective model of educational practice and its overdependence on Schön's theory. If its key concepts are "inquiry, community, rationality, judgement, creativity, autonomy" (2003, 19), these are at such a level of general acceptance as to be less than useful in distinguishing ideas-and, ironically, in thinking critically in higher education. The strengths in Lipman's work reside in his mission to improve the quality of thinking in schooling.

More substantial than the critical thinking movement to date has been the informal logic movement, emerging in the late 1970s, and embracing theoretical, practical (including how best to structure arguments), and pedagogical issues. In many ways, informal logic provides a bridge between critical thinking and its varied application in higher education institutions on the one hand, and linguistic and discourse analysis on the other. Behind the informal logic movement is a longer tradition of classical and contemporary rhetoric, concerned with the deployment of thinking in the real world in the form of argumentation.

Lipman sums up the approaches well:

Informal logicians and rhetoricians attack the same problem from different directions... Both are examining claims to reasonableness (and therefore are concerned with a theory of rationality). But the informal logicians move 
towards a new conception of reasonableness by broadening and refining the concept of logic, while the rhetoricians do so by examining writing that is not or does not appear to be formally logical, in an effort to determine what justification such prose may claim to being reasonable. Moreover, both are inclined to focus on argumentation, but the one group emphasizes the persuasive force of argument while the other emphasizes its logical force. $(2003,42)$

Ennis (1987), suggests Lipman (ibid., 46ff), bases his approach to critical thinking on its power to help us decide what to "believe and do." Lipman is cautious about claims of this kind, preferring to see critical thinking as providing "a tentative scepticism" (47) rather than a justification of a set of beliefs or tools for making judgments and action. But Ennis's distinction between dispositions and abilities is useful in characterizing the field of critical thinking. In terms of dispositions, critical thinkers are concerned that their beliefs are true and their decisions justified; that their positions are reasonable, honest, and clear; and that others' views and feelings are respected. In terms of abilities, critical thinkers have the skills to clarify; justify the basis for decisions; infer, both deductively and inductively; make suppositions; and approach problems with equanimity, due sequence, and propriety with regard to rhetorical strategy.

Paul (1987), in the same volume as the chapter by Ennis, argues that critical thinking involves judgment, and judgment necessitates a consideration of context. Judgment, however, requires a disposition toward dialogue and dialectic.

Critical thinking, as a movement, has had more currency in the United States than the United Kingdom despite the launch of an Advanced Supplementary (AS) level examination for 16-17-year olds in critical thinking in the United Kingdom in 1999. The range of definitions tends to cluster around the notion of robust thinking skills, with the epithet "critical" adding an edge to the activity that suggests both meta-thinking about thinking and the deployment of philosophical analytical processes to the discussion of propositions and evidence. When characterized as a "movement" rather than a discipline or subject, critical thinking can be seen as a loose federation of pedagogical approaches designed not only to improve the quality of thinking generically, but also to raise awareness about the construction of discipline-based or subject-based knowledge. What is of concern with the movement, particularly as far as its application in higher education is concerned, is the lack of sharp focus as to its parameters, the lack of agreement about its internal definitions, and the lack of curricular space in higher education to deploy its insights effectively.

Kuhn (2005) is particularly critical of the broad and overdefined (and thus unclear) nature of the critical thinking movement, preferring to base her own work on empirical evidence (as opposed to most of the work on critical thinking); on cognitive development (often not addressed in higher education); and 
on life outside the school classroom. She divides her attention between the two elements necessary for more socially based thinking in and outside formal schooling and higher education: skills of inquiry and skills of argument.

A key issue for higher education is therefore: What is the balance between epistemological discipline-based enquiry on the one hand and generic critical thinking education on the other? I will return to this topic toward the end of this chapter in revisiting some of the findings of a study of undergraduate argumentation, undertaken at the University of York in the mid-2000s. In this study (reported in Andrews, Torgerson, Low, McGuinn, and Robinson 2006a; Andrews, Torgerson, Robinson, See, Mitchell, Peake, Prior, and Bilbro 2006b) aspects of the relationship between critical thinking and argument were explored. The focus on argumentational skills enables a return to the main focus of this chapter.

\section{Argumentation}

Argumentation-the more technical and process-based term than the more general "argument" - has a number of antecedents-mostly in the form of theories or disciplines. Among these are dialogism, discourse theory, linguistics, logic (especially informal logic), pragma-dialectics, speech act theory, communication theory, and classical and contemporary rhetoric. Such an eclectic pedigree may be due to the fact that argumentation is seen as central to everyday interaction as well as to local, national, and international politics. It is not possible in the confines of this chapter to give a full account of the derivation of argumentational practice in the light of all these theories and disciplines. I will focus particularly on the rhetorical dimensions of argument for the purposes of this chapter, as both classical and contemporary rhetoric have a theoretical as well as a practical application. Furthermore, in terms of the relationship with critical thinking, rhetoric provides a useful counterbalancing set of theories and practices. The present section will focus first on the practical aspects of argumentation in higher education, then come back to theoretical concerns via a look at rhetoric.

Argumentation is indubitably connected with higher education in that the most successful undergraduates tend to be those who can argue well, in speech and/or writing, whatever their discipline. Argumentation is assessable, and it increasingly appears in criteria for success at the highest levels of undergraduation. It is even more integral to masters or doctoral level work, often (now) appearing explicitly as a criterion for success. At the doctoral level, one could say that the thesis is the argument, and vice-versa; but the same is true, to different degrees, for masters and undergraduate assignments (and we must not forget that most undergraduate and masters degrees see the dissertation or report as the summation of study, with a significant proportion of the marks 
attributed to this final piece of work). At all levels, discipline-dependence ("field-dependence" in Toulminian terms) is a significant factor and needs to be balanced with generic argumentational skills ("field-independence"). Such a balance is the basic position taken in Argumentation in Higher Education (Andrews 2009a).

Why is argumentation so important to higher education? It is about articulation in both senses of that word: both the expression of ideas, thoughts, feelings, and suppositions; the joining together of these ideas and notions in logical and quasi-logical sequences, supported (usually and beneficially) by evidence; and also the positioning of the student in relation to existing bodies of knowledge.

For the purposes of this section, I will concentrate on the doctoral thesis or dissertation, as work on argument in a range of undergraduate disciplines has been addressed elsewhere (Andrews 2002; 2009a; 2009b) and will be returned to in the final section. Work on masters-level argumentation has been addressed elsewhere (Andrews 2007).

Arguments emerge gradually in doctoral work. A student will first have a hunch that he or she wishes to do research in a particular field. The search then takes place, via the reading of existing literature as well as observation through experience and/or thought, for a problem. From the problem emerges either a research question (or set of related questions) and/or a hypothesis. Once a clear starting point has been established, and taking into account the flexibility needed in adjusting the question or hypothesis, the literature search is mapped and undertaken, the methodology and methods decided upon and piloted, and the work begins of creating a pathway through the field. It is this pathway that in due course becomes the argument.

One of the most critical decisions in composing a thesis or dissertation at this level is the structure of the piece. Is it to be linear (the conventional form) with an introduction followed by literature review chapters, followed by methodological considerations, and in due course by results, discussion, and conclusions? If so, what differences are there between the arts, humanities, and social sciences with regard to conventional linear structures? I have seen theses that follow this classic social science structure. But I have also seen examples of theses that are more narrative and autobiographical in nature; that follow the introduction with a brief methodological discussion; that do not follow the classic structure at all, but take a philosophical or at least reflective excursion through a field; that do not have "results" as such; that are more like the structure of Sterne's Tristram Shandy (Sterne 1759-67), a work published over several years with a combination of narratives, poems, illustrations, blank pages, and conventional academic argumentational text. Some of these theses translate readily into book form; others (perhaps the conventional model) do not. And yet linear structure is critical to the argument (post hoc ergo propter hoc), and, one could say, it is only proper that the supervisor advise the student on how 
best to meet the expectations and regulations and criteria of the university in which the thesis is being created. The only thesis I have ever recommended for failure, even at second attempt (there was no second attempt) had no such rationale for a structure of any kind: it was an assortment, a bricolage, a series of unconnected notes that could not justify itself, even in a postmodern sense, as having any kind of unity of argument, try as hard as the other examiner and I did to make connections between the various elements.

The elements of argument embedded within the conventional thesis are similar to those of classical rhetoric, the function of which was to ensure the quality of public oratory and debate in democratic society. The expectation is that there will be an introduction; a narration of the existing state of knowledge; a means by which that knowledge can be tested via empirical data gathering and analysis, and/or via reflection; a discussion of the state of existing knowledge in relation to new knowledge created; and a conclusion that looks back at the starting point of the research, and then forward to future research, and to applications of the research in policy and practice. But the argument does not emerge until the researcher is well into the process of research. Once its lineaments become clearer, it affords structure and direction to the thesis. By the time the thesis is submitted, and in the viva voce examination that follows, the argument should be clear, defensible, open to question, and well supported by evidence and/or logical or quasi-logical reflection.

What happens to argument and argumentation when the thesis moves away from linearity toward a more hypertextual, spatial, and generally nonlinear format? The creation and submission of alternative forms of thesis, like a website, an art installation, a film-forms which are becoming increasingly common, partly as a result of the digitization of the doctoral research process and product (see Andrews, Borg, Boyd Davis, Domingo, and England 2012)—present interesting challenges to the student, supervisor, and examiner in terms of where the argument sits. If the argument is central to the thesis in the arts, humanities, and social sciences in the European humanistic tradition, where is it in a digitized work like a website? First, it should be acknowledged that such alternative forms of submission for the award of $\mathrm{PhD}$ tend to hedge their bets by insisting that the "creative' component" is accompanied by a critical commentary in writing of about half the length of a conventional thesis, and representing about half of the submission itself. Thus an exhibition of paintings or sculptures, a website, or a film would be usually accompanied by a $40-50,000$ word catalogue or critical commentary where the argument could be explicitly stated. But we also have to acknowledge that the creative work itself embodies an argument. Let us take a website submission, for example. It might include various sections that are hypertextually related, and all accessible from the front page. These sections might include still and moving images and sound files, hypertextual links to other sites and sources, as well 
as conventional argumentational and nonconventional written text (remember Tristram Shandy). The key point as far as argumentation is concerned is that there is no linear sequence in which one is expected to read the doctoral submission. You can "enter" at any of a number of points; you can read the various elements and sections in any order; and you can construct your own arguments, as a reader, that may or may not reflect the implicit or explicit arguments of the composer. An example of such a work is by Milsom (2008) in which the opening page of the submission is a photograph of the researcher's desk (see also Milsom 2012). The photograph is interactive in that the drawers, folders, books, notebook, computer, Post-It notes, etc. are points via which one can access the various elements that make up the submission.

Panning out from these practicalities of constructing arguments for the doctoral thesis, what are the rhetorical considerations relevant to argumentation in higher education? While rhetoric for Aristotle was defined as the art of persuasion, contemporary rhetoric concerns itself more broadly with the arts of discourse, and is applicable in a wide array of situations, from the personal to the political, and in a range of modes and media. It basically answers the questions: Who is communicating to whom? What about? What are the available means (modes and media) of communication? Which are best used, in which combinations, to ensure successful communication? How is that communication effected? It embraces many of the considerations listed above in the opening paragraph: dialectics and pragma-dialectics, dialogism, speech act theory, linguistics, and discourse theory. What it does not tend to do, and where the link with critical thinking will be explored later in the chapter, is to ask why such communicative exchanges are undertaken.

In the examination of the doctoral thesis, in the United Kingdom at least, the genre (in the sense of genre as social action, not as text type-see Miller 1984) concerns the presentation of a work, either in conventional format or within the regulations of the particular university, and a discussion between the examiners and the candidate (with sometimes the supervisor present as a silent witness) of that work. The examiners are usually asked to submit independent reports, giving a provisional judgment on the submitted work, prior to the viva, and which they exchange in order to see to what degree their views are similar or different. They then conduct the discussion accordingly. All the power rests with the examiners-especially the external examiner, who, besides judging the work itself, is judging the standards of the institution itself. The "external," therefore, has the more powerful voice in the final outcome. In rhetorical terms, then, we have a submitted work on the table where the argument is put explicitly, or somewhere on a spectrum from the implicit to the explicit; the researcher is there to defend both his or her decisions in the process of undertaking the work, and the product itself; he or she does so by adding to the written submission with verbal (oral) commentary 
and responses to the examiners' questions. The whole is framed by the criteria for the award of a doctorate at the institution in question, as well as by the experience of the examiners in seeing other such works recommended for a "pass," both in the present institution, and in others. There are other hidden criteria at play: the elegance of the submission, the appropriateness of the researcher joining the "community" of those with a doctoral degree; and sometimes (unfairly, often) the prejudices of the examiners for particular kinds of work they wish to see exhibited (e.g., preference for a particular methodology or research paradigm; the degree to which they see required corrections as minor or major amendments). The criteria for the award of a doctorate always include some reference to argumentation: a "clear line of argument" or "a coherent and critical argument, well supported by evidence and/or logic," for example. If a candidate can see that argumentation is critical to success, it usually does not matter that the examiners may agree or disagree with his or her argument; the path to success is to argue well, both in the presented text and in the viva. Where theses are likely to fail or be referred for further work, the argument is either nonexistent, flawed or half-baked; and the questions of the examiners in this respect are unanswered or answered badly.

The rhetoric of the thesis and of the viva, then, is part ritual, part a genuine attempt by the examiners to elicit the argument put forward by the candidate for the award. Understanding the rhetorical context is important for the supervisor and candidate. For example, colleagues and I have noticed a tendency in theses in education and the social sciences over the last ten years or so to have increasingly large sections on methodology, and increasingly small sections on theory, perhaps reflecting tendency to validate generic methodological competence at the end of a period of doctoral study rather than, say, grasp of a particular field. Candidates must be able to defend their thesis by understanding where the examiners are "coming from," that is, what ideologies and values and past experience, expertise, and interests they are bringing to the inevitably intersubjective nature of the examination. Candidates also need to understand that an immediate and unqualified pass at doctoral level is being increasingly replaced by a desire, on the part of examiners, to treat the thesis like a draft book, and to suggest amendments, corrections, and other improvements-within the confines of the regulations and options open to them as examiners. In the United Kingdom, at least, the $\mathrm{PhD}$ viva is becoming more like a very unbalanced peerreview occasion. Very few candidates ever "fail," but minor corrections and more substantial amendments, including referrals for further work, are increasingly de rigueur. The social and political framing of the event is rhetorically informed, and the arguments within it are influenced accordingly.

Argument, within a theory of classical or contemporary rhetoric (Andrews 2014), is a means by which agreement and consensus (or at least, a way forward, even if, in the case of the viva described above, the relationship between 
the parties is unequal) are reached; a form of discourse in which excellence is expected at the summation of degree courses; a process which is undertaken in a range of modes and media; and a process in which difference is explored in order to, in due course, clarify positions and reach consensus for action.

\section{Critical thinking and argumentation}

Much of the work on bringing together critical thinking and argumentation has already been done by Walton (2008); indeed, the term "critical argumentation" in the preface to the second edition of Informal Logic indicates the nature of the relationship. "Informal" indicates a grounding of arguments "as they occur in natural language in the real marketplace of persuasion on controversial issues in politics, law, science, and all aspects of daily life" (2008, xi) - -hence the subtitle of the book: "A Pragmatic Approach." Such an approach sets argumentation within a dialogic frame, assuming that "the concept of question-reply dialogue as a form of interaction between two participants, each representing one side of an argument" $(2008$, xii) is fundamental to the study of argumentation in society. The notion of informal logic has suggested groundedness in specific contexts, rather than informality per se; the aim has continued to be identification of general patterns of logic in everyday argumentational discourse. As Walton notes, "what is happening now could be described as a movement from informal logic to semi-formal logic" (2008, xiii)-in other words, the gradual identification of laws and patterns in argumentation that are emerging in fields as diverse as computing, linguistics, discourse analysis, and dialectics. Informal logic and argumentation are steadily establishing themselves as more reliable and coherent tools for the examination of dialogic exchange in everyday life and in academia.

One particular context for critical argumentation is higher education. In a study undertaken with co-researchers at the University of Illinois at UrbanaChampaign, Queen Mary, University of London, and the University of York (Andrews et al. 2006a; Andrews et al. 2006b) and later written up (Andrews 2009a) as part of a book on argumentation in higher education, investigation was undertaken into first-year argumentation in three disciplines: biology, electrical engineering, history, with subsequent research on educational studies. My own reflections on the project are influenced by reading in rhetoric and argumentation; reading on research in writing development in schools; and experience of teaching within the US and UK higher education systems.

Essentially, the development of argumentational skills in higher education appears to be based on the combination of a number of key elements:

1. a disposition on the part of students to be "critical," that is to weigh up different points of view; to be able to separate claims and propositions from 
evidence; to question received assumptions; to hold a skeptical attitude toward "facts" and assumptions,

2. a disposition on the part of university lecturers and professors to accept and promote such a critical approach,

3. a knowledge of some of the theories and models of argumentation that have application in a generic sense,

4. an awareness of the way argument is manifested and structures the nature of particular disciplines,

5. the disposition, on the part of lecturers and students, to "drill down at the points of dispute" within a discipline where knowledge is contested, and

6. an understanding on the part of lecturers and students that development of such argumentational skills is expected within the period of study for a degree, and if not formed at the start, will go through a number of stages.

\section{A disposition to be critical}

Criticality in students' work is highly prized, and even if it is not mentioned in criteria for the grading of undergraduate essays, masters assignments and dissertations, and doctoral theses, is always a hidden criterion in the judgment of excellence and-for many students-a key distinguishing feature between work that is mediocre and work that is rated as very good and above. To be critical means drawing on the largely European tradition of critique: being driven by "suspicion" and skepticism rather than by obedience or deference to the presented truth; weighing up validity claims against each other; testing the warrants that hold together claims/propositions on the one hand, and data and evidence on the other; and developing a critical stance or position, which often emerges after a great deal of reading and reflection in the field or on the topic. None of these features are easy options for students to take. They require independent thought and hard work in reading and research.

\section{Lecturers' disposition to celebrate the critical}

Many lecturers in higher education do not accept that their positions can be criticized; that their take on knowledge is partial; or that their authority in the lecture hall or seminar room can be questioned. And yet teaching a critical approach, and celebrating the critical spirit, requires humility with regard to one's own knowledge and a sense that it could be improved by the application of criticality. Such an open approach to the fostering of criticality requires knowledge to be seen as provisional; expertise as always emergent; and student voices to be heard in the discussion and debate of key topics in the field or discipline.

\section{Knowledge of key theories and models of argumentation}

To argue well, it is helpful to know how argument is constructed. There is no single model to fulfill this need, and attempts to apply or adapt Aristotelian 
and other forms of classical rhetoric to the needs of the modern student only offer partial success. For example, it is helpful to know that arguments are composed of constituent parts; that these parts can be arranged in different sequences (there is no agreement in classical rhetoric as to how many); that proposition must be linked to evidence ("statement" to "proof"); and that weaker parts of the argument should be positioned in the middle of the essay or speech. But the classical emphasis on the character of the speaker, on feeling, and on persuasion in an oral public forum are not always transferable to the seminar presentation or the essay/dissertation. Classical rhetoric needs to be complemented by twentieth- and twenty-first-century thinking on argumentation, like that of Toulmin (1958), Yoshimi (2004), and Kaufer and Geisler (1991), each of whose models offers something to students at different stages in the composition of an argument (Andrews 2005).

\section{Awareness of the way argument manifests itself in different disciplines}

There may be generic skills in argumentation that are helpful to teach and learn, but the subject- or discipline-specific elements of argument are likely to be of more immediate interest to the student of a particular discipline. We could say that it is the very nature of disciplines to create parameters within which argumentation of a particular kind is undertaken: where the disputes in the field are played out. For example, what does it take to argue as a student of an undergraduate degree in History, as opposed to one in Literature, Biology, or Engineering? Arguments in History may drill down at the points of dispute in the field; they may move from tertiary evidence to secondary and then primary evidence; in many ways argument is the sine qua non of History. Literature study is different in that arguments are more inductive and lead to appreciation and interpretation. In Biology, at undergraduate level, arguments are less likely to emerge as core to a study of the discipline unless there are sociopolitical dimensions of biology that are addressed; and in Engineering, the argument can be made in at least two forms: one, in the design of a product, and other in the presentation and justification of that product design to an audience.

\section{Drilling down at the point of dispute}

It was mentioned in the paragraph above that historians "drill down at the points of dispute" to explore the arguments in the field. But there are such points of dispute in all disciplines in higher education. While knowledge may be presented as noncontroversial in some early stages in the study of a subject, all disciplines provide space for the discussion of key problems. Undergraduate students who do not locate these points of dispute tend to see the field as unproblematic and tend to write middle-ranging essays that are 
more expository than argumentational. To achieve higher recognition in work at undergraduate, masters, and doctoral levels, the points of dispute-and their precise delineation-must be discovered. Then the student must have the courage and know-how to "drill down" to understand and reveal, if not necessarily solve, the disputes. Such drilling down always opens up ground for discussion and argumentation.

\section{The development of argument skills during a degree}

Becoming a critical thinker as an undergraduate is a matter of development. It is not expected that all undergraduates, at the start of their studies, have fully formed argumentational skills in their chosen fields. Those who start with an understanding of and skills in argumentation are at an advantage; they will hone their skills through discussion, feedback from tutors, and through their ability to manage complex aspects of a discipline with agility and depth. But many students will arrive at the beginning of a course of study without such highly developed skills. It is the aim of many undergraduate courses to equip students to be able to argue well. To be a historian, for example, you need to be able to think and argue like a historian. To then undertake a masters in the field, you need to attain "mastery"; and to undertake doctoral work, you will be expected to contribute to the field itself. Each stage of undergraduate and graduate education requires a further improvement in argumentation skill and capability.

\section{Conclusion}

We conclude that one way to encourage critical thinking in higher education is through an increased focus on argumentation. Argumentation implies criticality; the one cannot function without the other. But thinking, as those in the field suggest, can take various forms, from critical thinking to creative thinking, from naturally occurring cognitive development to productive thinking (see Moseley, Baumfield, Elliott, Gregson, Higgins, Miller, and Newton 2005). To provide the epithet "critical" to thinking processes and procedures appears tautological, unless one wishes to distinguish such different kinds of thinking. But the categorization of the range of ways of thinking has not been the principal driver behind the critical thinking movement. Rather, the movement has identified generic thinking skills that have been separated from context and taught as an abstract mode of operation.

Recent studies in argumentation, on the other hand, have acknowledged that generic argumentational skills can only provide a framework, and that discipline-specific argumentation in higher education is an essential counterweight to the more general approach. The advantage of taking an argumentational perspective, rather than one on critical thinking, is that argumentation 
can be concretized; it has a variety of models that can be applied to writing, speaking, and composing; it manifests itself in one or a number of modes; and there are distinct ways in which argued positions can be challenged.

If the aim of a focus on thinking and argumentation is to help students to sharpen the focus of their studies and to improve the quality of their engagement in speech, writing, and other modes, then the provision of short courses in argumentation at the beginning and toward the end of their studies, supplemented by in-depth exploration of how their chosen disciplines work, would seem the best way forward. Ultimately, the provision of such generic and discipline-specific argumentational strands will produce students who, once they graduate, are able to think clearly, argue well, and take their place in a democratic society where difference is tolerated, understood, and, where possible, resolved to allow consensus and action. If they progress to further study at postgraduate level, the aim becomes one in which a deep and synoptic understanding of complexity in a chosen field and topic is attained, coupled with a coherent argument that is able to present and defend such complexity in accessible and contestable terms.

\section{References}

Andrews, R. 2002. "Argumentation in Education: Issues Arising from Undergraduate Students' Work." In Proceedings of the Fifth Conference of the International Society for the Study of Argumentation, edited by F. H. van Eemeren, J. A. Blair, C. A. Willard, and F. S. Henkemans. Amsterdam: SicSat (International Center for the Study of Argumentation). 17-22.

Andrews, R. 2005. "Models of Argumentation in Educational Discourse." Text 25 (1): 107-127.

Andrews, R. 2007. "Argumentation, Critical Thinking and the Postgraduate Dissertation." Educational Review 59 (1): 1-18.

Andrews, R. 2009a. Argumentation in Higher Education: Improving Practice through Theory and Research. New York: Routledge.

Andrews, R. 2009b. "A Case Study of Argumentation in Undergraduate Level History." Argumentation 23 (4): 547-558.

Andrews, R. 2014. A Theory of Contemporary Rhetoric. New York: Routledge.

Andrews, R., Borg, E., Boyd Davis, S., Domingo, M., and England, J. 2012. The Sage Handbook of Digital Dissertations and Theses. London: Sage.

Andrews, R., Torgerson, C., Low, G., McGuinn, N., and Robinson, A. 2006a. Improving Argumentative Skills in Undergraduates: A Systematic Review. New York: Higher Education Academy.

Andrews, R., Torgerson, C., Robinson, A., See, B. H., Mitchell, S., Peake, K., Prior, P., and Bilbro, R. 2006b. Argumentative Skills in First Year Undergraduates: A Pilot Study. New York: Higher Education Academy.

Ennis, R. H. 1987. A Taxonomy of Critical Thinking Dispositions and Abilities. In Teaching Thinking Skills: Theory and Practice, edited by J. B. Baron and R. J. Sternberg. New York: W. H. Freeman and Company. 9-26.

Kaufer, D., and Geisler, C. 1991. " A Scheme for Representing Academic Argument." The Journal of Advanced Composition 11 (Winter): 107-122.

Kuhn, D. 2005. Education for Thinking. Cambridge, MA: Harvard University Press. 
Lipman, M. 2003. Thinking in Education. (second edition). Cambridge: Cambridge University Press.

Miller, C. 1984. "Genre as Social Action." Quarterly Journal of Speech 70: 151-167.

Milson, A.-M. 2008. Picturing Voices, Writing Thickness: A Multimodal Approach to Translating the Afro-Cuban Tales of Lydia Cabrera. unpublished PhD dissertation, Middlesex University, London.

Milsom, A.-M. 2012. Translating Lydia Cabrera: A Case Study in Digital (Re)Presentation. In The Sage Handbook of Digital Dissertations and Theses, edited by R. Andrews, E. Borg, S. Boyd Davis, M. Domingo, and J. England. London: Sage. 276-297.

Moseley, D., Baumfield, V., Elliott, J., Gregson, M., Higgins, S., Miller, J., and Newton, D. P. 2005. Frameworks for Thinking: A Handbook for Teaching and Learning. Cambridge: Cambridge University Press.

Paul, R. W. 1987. Dialogical Thinking: Critical Thought Essential to the Acquisition of Rational Knowledge and Passions. In Teaching Thinking Skills: Theory and Practice, edited by J. B. Baron and R. J. Sternberg. New York: W. H. Freeman. 127-148.

Sterne, L. 1759-67. The Life and Opinions of Tristram Shandy, Gentleman. London: Ann Ward (vol. 1-2), Dodsley (vol. 3-4), Becket \& DeHondt (5-9).

Toulmin, S. E. 1958. The Uses of Argument. (first edition). Cambridge: Cambridge University Press.

Walton, D. 2008. Informal Logic: A Pragmatic Approach. (second edition). Cambridge: Cambridge University Press.

Yoshimi, J. 2004. "Mapping the Structure of Debate." Informal Logic 24 (1): 1-21. 